\title{
PREVALENCE OF HELICOBACTER PYLORI INFECTION IN PATIENTS WITH PORTAL HYPERTENSION
}

\author{
Shatdal Chaudhary, ${ }^{1}$ Altaban Rahi, ${ }^{2}$ Anita Shah, ${ }^{3}$ Aakash Shahi, ${ }^{1}$ Badri Kumar Gupta, ${ }^{4}$ Niraj Kumar Jaiswal ${ }^{1}$
}

\begin{abstract}
INTRODUCTION

Helicobacter pylori (H. pylori) is a microaerophile gram-negative bacillus which is found mainly on the surface of mucous membrane of the prepyloric part of the stomach. It is found to be infecting approximately $50 \%$ of world population. In patients with liver cirrhosis, the prevalence of $H$. pylori is variable. A high incidence of $H$. pylori colonization has been found in portal hypertension; especially in those with gastric erosion. This study was done to find out the prevalence of $H$. pylori infection in patients with portal hypertension at Universal College of Medical Sciences Teaching Hospital, Nepal.
\end{abstract}

\section{MATERIAL AND METHODS}

It was a hospital based cross sectional observational study. All the consecutive patients aged more than 16 years, presented with portal hypertension who fulfilled the inclusion criteria were included in the study. The study period was from $1^{\text {st }}$ September 2015 to $31^{\text {st }}$ August 2016. The upper gastrointestinal endoscopy was done in all cases and mucosal biopsy was taken. $H$. pylori infection was diagnosed by using rapid urease test.

\section{RESULTS}

During the study period, 71 patients fulfilled the inclusion criteria and were included in the analysis. The majority of the patients 21 (29.6\%) were between 51-60 years age group. There were more male $(78.9 \%)$ then female $(21.1 \%)$. The mean age of study population was $50.85 \pm 12.47$ years. Among the study population, rapid urease test was positive in $70.4 \%(\mathrm{n}=50)$ patients.

\section{CONCLUSION}

The prevalence of $H$. pylori infection was seen in $70.4 \%$ of the patients suffering with portal hypertension.

KEY WORDS Chronic liver disease, Helicobacter pylori, portal hypertension, rapid urease test

1. Department of Internal Medicine, Universal College of Medical Sciences, Bhairahawa, Nepal

2. Department of Medicine, Bheri Zonal Hospital, Nepalgunj, Nepal

3. Department of Pathology, Universal College of Medical Sciences, Bhairahawa, Nepal

4. Department of Pediatrics, Universal College of Medical Sciences, Bhairahawa, Nepal

DOI: https://doi.org/10.3126/jucms.v6i2.22470

For Correspondence

Dr. Shatdal Chaudhary,

Department of Internal Medicine,

Universal College of Medical Sciences,

Ranigaon, Bhairahawa, Nepal.

Email: shatdalchaudhary@yahoo.com 


\section{INTRODUCTION}

Helicobacter pylori (H.pylori) is a spiral, Gram-negative, microaerophilic bacterium. Worldwide approximately $50 \%$ of human population is infected with $\mathrm{H}$. pylori. The rate of infection is even higher in developing countries which can reach more than $70 \%$ of population. ${ }^{1,2}$ Infection is highly prevalent, especially in low socioeconomic strata of developing countries. ${ }^{3}$ H. pylori infection is known to be associated with development of various of gastrointestinal tract diseases like gastritis, peptic ulcers, gastric cancer, mucosa-associated lymphoid tissue (MALT) lymphoma and biliary tract cancer. ${ }^{4}$ Portal hypertension is one of the common medical conditions encountered in gastroenterology practice. Porta hypertension is defined as the elevation of the hepatic venous pressure gradient (HVPG) to $>5 \mathrm{mmHg} .^{5}$ Common causes of portal hypertension are cirrhosis of liver, non-cirrhotic portal fibrosis and extra hepatic portal vein obstruction due to umbilical sepsis. Common complications of portal hypertension are gastrointestinal haemorrhage, hepatic encephalopathy, hepatorenal syndrome, and ascites which are associated with significant morbidity and mortality. ${ }^{6}$ Patients with liver cirrhosis and portal hypertension are widely accepted to be at risk of developing acute upper gastrointestinal bleeding. ${ }^{7,8}$

The risk is believed to be dependent on severity of liver dysfunction and the degree of portal hypertension. Ruptured esophageal varices and/or gastric varices account for the majority of bleeding episodes in these patients, whereas gastroduodenal ulcers, portal hypertensive gastropathy, Mallory-Weiss tear and duodenal varices are less frequent causes of bleeding. ${ }^{7-9}$ The incidence of portal hypertensive gastropathy in patients with cirrhosis and portal hypertension ranges from $9 \%$ to $80 \%{ }^{10-13}$ In patients with liver cirrhosis, the prevalence of H. pylori and it's associations with portal hypertensive gastropathy is controversial. ${ }^{14-16}$ A high incidence of $H$. pylori colonization has been found in portal hypertension, especially in those with gastric erosion. The topic of varices is well studied; however, prevalence of $H$. pylori infection and the mucosal changes in the patients with portal hypertension needs further elaboration. Therefore, this study was done to see the prevalence of $H$. pylori infection in patients with portal hypertension by using rapid urease test. This study will be useful in the management of upper gastrointestinal bleeding in patients with portal hypertensive gastropathy by planning the eradication of $H$. pylori.

\section{MATERIAL AND METHODS}

This was a cross-sectional observational hospital based study conducted in the department of internal medicine, Universal College of Medical Sciences, Bhairahawa, Nepal. The duration of the study was one year from $1^{\text {st }}$ September 2015 to $31^{\text {st }}$ August 2016. This study was approved by the ethical review committee of the institute. Written informed consent was taken from all the patients. Simple random selection of the patients aged $>16$ years with portal hypertension admitted in the department of internal medicine, Universal College of Medical Sciences, Bhairahawa was done during the study period. Portal hypertension was diagnosed based on the ground of clinical examination, and abdominal ultrasound doppler study. Abdominal ultrasound doppler study was done to look for splenomegaly, portal vein diameter $>13 \mathrm{~mm}$, portal systemic collateral, extrahepatic or portal vein obstruction, increased hepatic echogenicity and presence of ascites. Patients who did not give written consent for the study or aged $<16$ years were excluded. Patients who had history of recent myocardial infarction, arrhythmia, unconscious, uncooperative, restless or in shock, unfit for endoscopy were also excluded

After enrollment in the study, data was collected as per predesigned proforma. Detailed history, general and systemic examination was performed. Laboratory tests such as hemoglobin ( $\mathrm{Hb})$, blood group, total leukocyte count (TLC), differential leucocyte count (DLC), platelet, bleeding time (BT), clotting time (CT), prothrombin time (PT), international normalized ratio (INR), liver function test (LFT), renal function test (RFT), sodium $(\mathrm{Na})$, potassium $(\mathrm{K})$, random blood glucose (RBS), hepatitis B surface antigen, anti hepatitis $C$ antibodies, human immune deficiency virus I and II were done. Ultrasonography of abdomen and pelvis with color doppler with particular emphasis on portal vein diameter, portal systemic collaterals, extrahepatic or portal vein obstruction, hepatic echogenicity, splenomegaly, presence of ascites was done.

The upper gastrointestinal (UGI) endoscopy was done in all cases on the same day of presentation, if they presented during working hours or the next immediate working day. But patients who were hemodynamically unstable, endoscopy was done after resuscitation and stabilization of the patients. Fujinon video-endoscope model EG-250WR5 was used for the endoscopy. The endoscopy was performed in the endoscopy room under $10 \%$ lignocaine spray by an experienced endoscopist. Patient was kept fasting for six hours before the procedure. Endoscopy was performed in left lateral position. The stomach and upper duodenum was visualized for the changes, especially by taking the tip of the instrument close to the mucosa. The fundus was carefully looked to detect the portal hypertensive gastropathy, fundal varices and gastric varices. Rapid urease test was done for the diagnosis of $\mathrm{H}$. pylori. A biopsy of mucosa was taken from the antrum of the stomach, and was placed into a medium containing urea and an indicator such as phenol red, and left for $24 \mathrm{hrs}$. The enzyme urease produced by $H$. pylori hydrolyzes urea to ammonia, which raises the $\mathrm{pH}$ of the medium, and changes the color of the specimen from yellow (negative) to red (positive) which was noted. Statistical analysis was done using Statistical Package for Social Service (SPSS) version 20 for window software. Categorical data were expressed as frequencies and corresponding percentage. Pearson chi square test was used. Level of significance for all analytical tests were set at 0.05 and p-value $<$ 0.05 was considered to be statistically significant.

\section{RESULTS}

During the study period, 71 patients with portal hypertension were enrolled and analysed. In this study, there were $56(78.9 \%)$ male and $15(21.1 \%)$ female. Male and female ratio was about $4: 1$. The mean age was $50.85 \pm 12.47$ years. In this study, the minimum was 18 years and maximum age was 75 years. Among these, 21(29.6\%) patients were between 51-60 years, 20(28.2\%) patients were between 41-50 years, $11(15.5 \%)$ patients were between $31-40$ years, $10(14.1 \%)$ patients were between 31-40 years. Baseline characteristic of patients with portal hypertension are given in table below (Table 1). 
Table 1. Baseline characteristics of study population

\begin{tabular}{|l|l|}
\hline Variables & Mean \pm S.D. \\
\hline Age $($ years $)$ & $50.85 \pm 12.46$ \\
\hline Body mass index $\left(\mathrm{Kg} / \mathrm{m}^{2}\right)$ & $26.22 \pm 3.33$ \\
\hline Pulse (beats per minute) & $86.01 \pm 12.63$ \\
\hline Hemoglobin $(\mathrm{gm} / \mathrm{dl})$ & $8.18 \pm 2.11$ \\
\hline Total leukocyte count $\left(/ \mathrm{mm}^{3}\right)$ & $8346 \pm 2991.50$ \\
\hline Platelets $\left(/ \mathrm{mm}^{3}\right)$ & $1.72 \pm 0.37$ \\
\hline SGOT $(\mathrm{IU} / \mathrm{l})$ & $76.35 \pm 9.39$ \\
\hline SGPT $(\mathrm{IU} / \mathrm{l})$ & $40.50 \pm 27.30$ \\
\hline INR & $1.47 \pm 0.74$ \\
\hline
\end{tabular}

There were 33 (46.5\%) farmers, 7 (9.9\%) servicemen, $11(15.5 \%)$ housewives, $12(16.9 \%)$ businessmen, and $8(11.3 \%)$ labourer by occupation. Almost all female were exclusively housewives whereas majority of patients were farmers. H.pylori infection was detected by rapid urease test. It was found positive in $50(70.4 \%)$ patients and negative in $21(29.6 \%)$ patients (Figure 1).

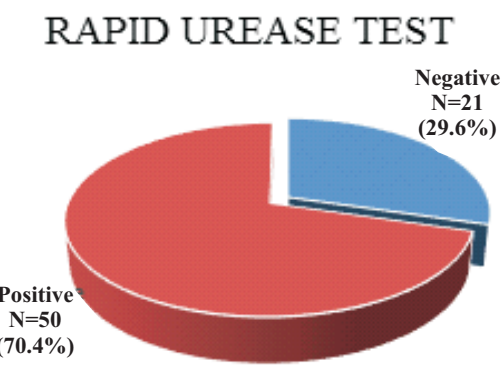

Figure 1. Distribution of cases $(n=71)$ based on rapid urease test for $H$. pylori

\section{DISCUSSION}

This was a hospital based cross-sectional observational study done to find the prevalence of H.pylori infection in patients of portal hypertension. Most of the patients belonged to the age group of 51 to 60 years $(29.6 .7 \%)$ followed by 41 to 50 years $(28.2 \%)$. In a similar study done by Karki et al, the prevalence of portal hypertension was $30 \%$ among 40 to 49 years age group. ${ }^{17}$ Among the study population there were $56(78.9 \%)$ males and $15(21.1 \%)$ females. Male predominance was seen in this study and was similar to findings noted in a study by Pathak OK et al (2009) where 80.7\% among 181 patients were males. ${ }^{18}$ Higher incidence in male was also reported by Paul SB et al (2007) with a M: F ratio of 6.1:1 among cirrhotic. ${ }^{19}$ This difference is due to high incidence of ethanol intake among men compared to women, which is the major etiology of chronic liver disease and also due to differences in the medical care seeking practice among both sexes as here is the male dominant society. In this study, the majority of the study population were farmers (46.5\%) who usually belong to the low socioeconomic status in our part. In a study done by Goel A et al (2013), majority belonged either to middle class $(n=329 ; 70 \%)$ or lower class. ${ }^{20}$ Studies have found an association between low socioeconomic status and increased cirrhosis incidence. ${ }^{21-23}$

In this study, among the study population, rapid urease test was positive in $70.4 \%$ and negative in $29.6 \%$. Regardless of the cause of portal hypertension, many patients with this condition demonstrate endoscopic findings described as portal hypertensive gastropathy. Portal hypertensive gastropathy is a frequent cause of bleeding in patients with portal hypertension due to gastric mucosal capillary dilatation. The mucosa is increasingly susceptible to agents such as bile acids, aspirin and alcohol. Reports on whether H.pylori infection can be a risk factor in the development of portal hypertensive gastropathy are conflicting. A Chinese study by Yang et al investigated the possible relationship between $H$. pylori infection and portal hypertensive gastropathy in cirrhotic patients and suggested that H.pylori colonization of the stomach of cirrhotic patients was likely to be contributory to the pathogenesis of portal hypertensive gastropathy. ${ }^{24}$ In contrast, Balan et al reported detection of $H$. pylori in $40 \%$ of cirrhotic patients, a figure identical to the prevalence of the organism in the general population. They concluded that $H$. pylori infection is unlikely to be an important factor in the pathogenesis of portal hypertensive gastropathy and upper gastrointestinal bleeding. ${ }^{25}$

\section{CONCLUSION}

Portal hypertension occurred mostly in the middle age-group patients with male predominance. The patients were mostly farmers by occupation. H. pylori was detected in $70.4 \%$ of the study population by rapid urease test. From our study, we get encouragement to upgrade the socio economic condition of our country by raising awareness on proper sanitation, clean drinking water and personal hygiene.

\section{REFERENCES}

1. De Martel C, Ferlay J, Franceschi S, Vignat J, Bray F, Forman D, Plummer M. Global burden of cancers attributable to infections in 2008: a review and synthetic analysis. Lancet Oncol 2012; 13: 607-615.

2. Suerbaum S, Michetti P. Helicobacter pylori infection. N Engl J Med 2002; 347: 1175-1186.

3. Malatya HM. Epidemiology of Helicobacter pylori infection. Best Pract Res Clin Gastroenterol 2007; 21:205-214.

4. Shmuely H, Wattad M, Solodky A, Yahav J, Samra Z, Zafrir N. Association of Helicobacter pylori with coronary artery disease and myocardial infarction assessed by myocardial perfusion imaging. Isr Med Assoc J 2014; 16: 341-346.

5. Bacon BR. Cirrhosis and its Complications. In: Longo DL, Fauci AS, Kasper DL, Hauser SL, Jameson JL, Loscalzo J (editors). Harrison's Principle of Internal medicine. USA: Mc Graw-Hill Companies Inc; 2012: 308. 
6. Nusrat S, Khan MS, Fazili J, Madhoun MF. Cirrhosis and Its Complications: Evidence Based Treatment. World Journal of Gastroenterology 2014; 20(18):5442-5460.

7. Rabinovitz M, Yoo Y, Schade RR, Dindzans VJ, Thiel DH, Gavaler JS. Prevalence of endoscopic findings in 510 consecutive individuals with cirrhosis evaluated prospectively. Dig Dis Sci 1990; 35:705-710.

8. de Franchis R and Primignani M. Natural history of portal hypertension in patients with cirrhosis. ClinLiver Dis 2001; 5: 645-663.

9. Terdiman JP. The importance of accurate diagnosis and vigorous care of the patient with liver disease and gastrointesti nal hemorrhage. SeminGastrointest Dis 1997;8:166-178.

10. Primignani M, Carpinelli L, Preatoni P, Battaglia G, Carta A, Prada A et al. Natural history of portal hypertensive gastropathy in patients with liver cirrhosis. The New Italian Endoscopic Club for the study and treatment of esophageal varices (NIEC). Gastroenterology 2000; 119:181-187.

11. Iwao T, Toyonaga A, Sumino M, Takagi K, Oho K, Nishizono M et al. Portal hypertensive gastropathy in patients with cirrhosis. Gastroenterology 1992; 102:2060-2065.

12. Sarin SK, Shahi HM, Jain M, Jain AK, Issar SK, Murthy NS. The natural history of portal hypertensive gastropathy: influence of variceal eradication. Am J Gastroenterol 2000; 95: 2888-2893.

13. Zaman A, Hapke R, Flora K, Rosen HR, Benner K.Factors predicting the presence of esophageal or gastric varices in patients with advanced liver disease. Am J Gastroenterol 1999; 94: 3292-3296.

14. Durazzo M, Pellicano R, Premoli A, Berrutti M, Leone N, Ponzetto A et al. Helicobacter pylori seroprevalence in hepatitis C virus positive patients with cirrhosis. J Hepatol 2000; 33: 648-650.

15. Tsai CJ. Helicobacter pylori infection and peptic ulcer disease in cirrhosis. Dig Dis Sci. 1998; 43:1219-1225.

16. Yeh JL, Peng YC, Tung CF, Chen GH, Chow WK, Chang CS et al. Role of Helicobacter pylori in cirrhotic patients with dyspepsia: a ${ }^{13} \mathrm{C}$-urea breath test study. Adv Ther 2001; 18: 140-150.

17. Karki L, Gorkhaly MP, Karki BB. Study of upper gastrointestinal endoscopic findings in portal hypertension. $\mathrm{J}$ Nepal Med Assoc 2013; 52(190):337-42.

18. Pathak OK, Paudel R, Panta OB, Pant HP, Giri BR, Adhikari B. A retrospective study of the clinical profile and prognostic indicators in patients of ALD admitted to a tertiary care teaching hospital in West Nepal. Saudi J Gastroenterol 2009 July; 15(3) :171-175.
19. Paul SB, Sreenivas V, Gulati MS, Madan K, Gupta AK, Mukhopadhyay S, Panda SK, Acharya SK et al. Incidence of Hepatocellular carcinoma among Indian patients with cirrhosis of liver: an experience from a tertiary care centre in Northern India. Indian Journal of Gastroenterol 2007 Nov-Dec; 26(6) :274-8.

20. Goel A, Madhu K, Zachariah U, Sajith, KG, Ramachandran J, Ramakrishna B et al. A study of aetiology of portal hypertension in adults (including the elderly) at a tertiary centre in southern India. Indian J Med 2013 May; 137:922-927.

21. Najman JM, Williams GM, Room R. Increasing socioeconomic inequalities in male cirrhosis of the liver mortality: Australia 19812002. Drug Alcohol Rev 2007; 26:273-278.

22. Leyland AH, Dundas R, McLoone P, Boddy FA et al. Causespecific inequalities in mortality in Scotland: Two decades of change. A population-based study. BMC Public Health 2007; 7: 172 .

23. Lewis CE, Smith E, Kercher C, Spitznagel E. Predictors of mortality in alcoholic men: A 20-year follow-up study. Alcohol Clin Exp Res 1995; 19:984-991.

24. Yang DH, Huang CC, Yu JL, Song WS, Mao H, Xu C. The relationship between portal hypertensive gastropathy and $\mathrm{H}$. pylori infection. Chin J New Gastroenterol 1997; 5:27-8.

25. Balan KK, Jones AT, Roberts NB, Pearson JP, Critchley M, Jenkins SA. The effects of Helicobacter pylori colonization on gastric function and the incidence of portal hypertensive gastropathy in patients with cirrhosis of the liver. Am J Gastroenterol 1996; 91:1400-06. 